\title{
THE EFFECTS OF MAXIMUM STEADY STATE PACE TRAINING ON RUNNING PERFORMANCE
}

\author{
J. W. PRIEST, EdD and R. D. HAGAN, PhD* \\ Institute for Aerobics Research, Dallas, Texas \\ *Texas College of Osteopathic Medicine
}

\begin{abstract}
Maximum aerobic power $\left(\mathrm{VO}_{2}\right.$ max), maximum anaerobic power (AP max), submaximal exercise heart rate (HRsub), and performance times for distances of $15 \mathrm{~m}, 600 \mathrm{~m}, 3.22 \mathrm{~km}$, and $10 \mathrm{~km}$ were evaluated in 12 male runners prior to and after 7 weeks of a running programme at each individual's maximum steady-state (MSS) pace. MSS pace, a runnning speed at which blood lactate is believed to equal $2.2 \mathrm{mmol}^{-1-1}$, was calculated from weekly $3.22 \mathrm{~km}$ runs utilising the regression equation of LaFontaine et al (1981). During the training period, the mean MSS pace increased $11.3 \%$ from 3.76 to $4.19 \mathrm{~m} . \mathrm{s}^{-1}$. Body weight and maximal exercise heart rate were unaffected by MSS training. However, MSS training was associated with increases $(\mathrm{p}<0.05)$ in absolute $\mathrm{VO}_{2} \max (8.9 \%)$ and $\mathrm{VO}_{2}$ max relative to body weight $(8.1 \%)$, absolute AP max $(3.7 \%)$ and AP max, relative to body weight $(4.3 \%)$; decreases in resting HR $(5.4 \%)$ and HRsub $(6.9 \%)$; and decreases in performance times for runs of $15 \mathrm{~m}(1.8 \%), 600 \mathrm{~m}(4.4 \%), 3.22 \mathrm{~km}(9.6 \%)$, and $10 \mathrm{~km}(12.1 \%)$. MSS paces determined prior to the pre- and post-training $10 \mathrm{~km}$ races were significantly related to the pre-training $(r=0.98)$ and post-training $10 \mathrm{~km}(r=0.95)$ performance paces. Pretraining MSS pace, maximal aerobic power, and performance times for the $3.22 \mathrm{~km}$ and $10 \mathrm{~km}$ distances were highly related to improvements in MSS pace and performance times for the $3.22 \mathrm{~km}$ and $10 \mathrm{~km}$ runs. Our findings indicate that training at MSS pace is an effective method to increase maximal aerobic and anaerobic power, and decrease performance times for short- and middle-distance running events. Pre-training running performance may predict the magnitude of improvement due to MSS pace training.
\end{abstract}

Key words: Maximal steady state, Pace training, Maximal Aerobic power, Maximal anaerobic power, Running performance

\section{INTRODUCTION}

A number of regression equations which establish an individual's maximum steady-state (MSS) running speed have been developed for distances from 3.22 to $20 \mathrm{~km}$ (LaFontaine et al, 1981). MSS running velocity is defined as the running pace at which the blood lactate is approximately $2.2 \mathrm{mmol} . \mathrm{I}^{-1}$, and it has been suggested that the MSS pace is the optimal running speed for training and racing (LaFontaine et al, 1981; Londeree and Ames, 1975). Support for the MSS concept comes from studies in which distance running pace and performance are related to blood lactate levels (Costill et al, 1973; Farrell et al, 1979; Komi et al, 1981; Kumagai et al, 1982) Sjödin and Jacobs, 1981; Williams et al, 1967). However, the effectiveness of training at MSS pace on measures of maximum aerobic and anaerobic power and on performance times for short- and middle-distance running events is not known. At this time, no studies have attempted to evaluate the MSS training concept in a field setting.

Since, it has been reported that MSS pace and performance pace for distances between $3.22 \mathrm{~km}$ and $16.09 \mathrm{~km}$ are highly related, we decided to use the MSS equation for $3.22 \mathrm{~km}$ from a recent investigation to establish weekly MSS training paces (LaFontaine et al, 1981). In addition, the diversified training histories and levels of maximal aerobic power of our subjects allowed us the opportunity to examine how MSS training would effect runners with different performance potentials. Therefore, the purpose of this study was to evaluate the effectiveness of MSS pace training on selected measures of maximal aerobic and anaerobic power and on performance times for short- and middle-distance runs in a group of male runners.

Address for correspondence:

Dr. R. D. Hagan

Division of Health and Human Fitness

Department of Public Health and Preventive Medicine

Texas College of Osteopathic Medicine

Fort Worth, Texas 76107

\section{METHODS AND PROCEDURES}

Twelve males, members of a university cross-country team, volunteered to participate in this study. Six of the subjects, designated experienced runners, were welltrained and had a history of sustained aerobic conditioning. Three of these runners had at least three years of continuous high volume training and racing experiences, while the other three subjects had at least one year of high volume training and competitive races. The six remaining subjects were novice or recreational runners who had little to no competitive experience. The physical characteristics and training indices of the subjects are presented in Table I.

TABLE I

Physical characteristics and training indices of the subjects (Mean \pm S.D.)

\begin{tabular}{lccc}
\hline Variables & \multicolumn{3}{c}{ Groups } \\
\hline & $\begin{array}{c}\text { Experienced } \\
(\mathrm{n}=6)\end{array}$ & $\begin{array}{c}\text { Novice } \\
(\mathrm{n}=6)\end{array}$ & $\begin{array}{c}\text { Combined } \\
(\mathrm{n}=12)\end{array}$ \\
$\begin{array}{l}\text { Physical Characteristics } \\
\text { Age (yrs) }\end{array}$ & $19.3 \pm 0.52$ & $22.2 \pm 4.1$ & $20.6 \pm 3.1$ \\
$\begin{array}{l}\text { Height (cm) } \\
\text { Weight (kg) } \\
\text { pre-training }\end{array}$ & $179.6 \pm 5.2$ & $177.2 \pm 4.4$ & $178.4 \pm 4.7$ \\
$\quad$ post-training & $65.00 \pm 6.23$ & $70.48 \pm 5.37$ & $67.74 \pm 6.24$ \\
& $64.31 \pm 5.41$ & $70.06 \pm 4.91$ & $67.19 \pm 5.77$ \\
$\begin{array}{c}\text { Training Indices } \\
\text { Total Workout } \\
\text { Distance (km) }\end{array}$ & & & \\
$\begin{array}{c}\text { Total Workouts (\#) } \\
\text { Mean Workout } \\
\quad \text { Distance (km) }\end{array}$ & $905 \pm 352$ & $423 \pm 349$ & $664 \pm 418$ \\
& $70 \pm 7$ & $41 \pm 21$ & $56 \pm 21$ \\
& $13.0 \pm 5.2$ & $9.1 \pm 3.1$ & $11.0 \pm 4.6$ \\
\hline
\end{tabular}

In this study, MSS pace training was conducted for 7 weeks. During the 10 days prior to the commencement of MSS training, each runner was given a general orientation to the study, and a physical examination from a physician. All subjects completed and signed a form giving their voluntary consent to participate in the research project. Training during this period was voluntary and averaged 
4.8km per day per runner with the experienced runners accounting for $66 \%$ of this training.

During the 7 week training period, MSS training runs were conducted Monday through Thursday on a $\mathbf{4 0 0}$ metre track and over four different cross-country courses ranging in distance from 4 to $16 \mathrm{~km}$. All MSS training runs on the 400 metre track were supervised and running pace was maintained using a large dial field clock. During the initial weeks, training consisted of $\mathbf{4 0 0}$ metre distances run at MSS pace. Latter training sessions progressed to distances between $1.6 \mathrm{~km}$ to $5 \mathrm{~km}$ at MSS pace. After each day's MSS pace training on the track, the runners performed additional training runs at or near :MSS pace over the cross-country courses. The performance times for the runs were recorded and logged in each runner's training diary.

Each Thursday throughout the 7 week training period, the runners performed a $3.22 \mathrm{~km}$ run for best time. Individual performance times for the Thursday $3.22 \mathrm{~km}$ runs were converted to the average running pace $\left(\mathrm{m}^{\left.-s^{-11}\right)}\right.$ and entered into the $3.22 \mathrm{~km}$ equasion of LaFontaine et al

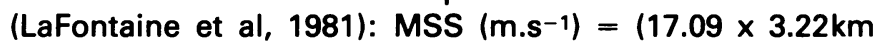
pace) - 54.3; where, MSS and $3.22 \mathrm{~km}$ pace are in $\mathrm{m}^{-s^{-1}}$. In addition, the MSS pace from the Thursday run was used to establish the subsequent week's MSS training pace. Mean $3.22 \mathrm{~km}$ pace runs and the predicted MSS training paces for all subjects combined prior to training average $4.40 \pm$ $0.67 \mathrm{~m} . \mathrm{s}^{-1}$ and $3.76 \pm 0.76 \mathrm{~m} . \mathrm{s}^{-1}$, respectively, while after the 7 week MSS training period the values were $4.76 \pm$

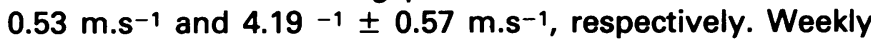
increases in mean $3.22 \mathrm{~km}$ and MSS pace averaged $1.16 \%$ and $1.61 \%$, respectively. On Fridays, all runners did only stretching exercises in preparation for the Saturday competitive races. Sundays were planned for rest and recovery, however, some of the runners utilised this time for a low intensity workout. Each runner maintained a diary of their training distances and duration for each run.

In our study, maximum oxygen uptake $\left(\mathrm{VO}_{2} \max \right)$ was determined utilising a treadmill test protocol (Bruce, 1971). These tests were conducted between 0800 and $1800 \mathrm{hrs}$ at $22-24^{\circ} \mathrm{C}$ and $42-54 \%$ relative humidity. The peak oxygen uptake for one minute during the test was taken as $\mathrm{VO}_{2}$ max. $\mathrm{VO}_{2}$ max was expressed as an absolute value (I.min-1) and relative to body weight $\left(\mathrm{VO}_{2} \max -\mathrm{BW}, \mathrm{ml}^{\mathrm{kg}} \mathrm{kg} \mathrm{min}^{-1}\right)$. On a separate day, a submaximal treadmill test was conducted during which the HR response was recorded during a six minute run conducted at $2.77 \mathrm{~m}^{-s^{-1}}$ on a horizontal treadmill. Maximal anaerobic power capacity (AP max), expressed in absolute terms as $W$ atts (W) and relative to body weight $\left(\mathrm{W} . \mathrm{kg}^{-1}\right)$, was determined during a $40 \mathrm{~s}$ pedalling test against a $5.5 \mathrm{kp}$ resistance on a Monark bicycle ergometer (Katch et al, 1974). A microswitch mounted on the frame and wired to an event marker recorded the total number of pedal revolutions.

All pre- and post-training field performance tests were conducted on a $\mathbf{4 0 0}$ metre all-weather (Chevron $\mathbf{4 0 0}$ surface) track and included the $15 \mathrm{~m}, 600 \mathrm{~m}, 3.22 \mathrm{~km}$ and $10 \mathrm{~km}$ run. During the $15 \mathrm{~m}$ run, the runners were timed as they ran between microswitches after a $50 \mathrm{~m}$ running start. During the $600 \mathrm{~m}, 3.22 \mathrm{~km}$ and $10 \mathrm{~km}$ runs, the subjects were instructed to run as fast as possible utilising the inside lane of the $400 \mathrm{~m}$ track.

The Wilcoxon matched-pairs signed-ranks test was utilised to evaluate pre- and post-test scores for all test measures (Siegel, 1956). An alpha level of 0.05 was accepted as significant. In addition, Pearson productmoment correlation coefficients were calculated for selected dependent and independent variables.

\section{RESULTS}

Resting, submaximal and maximal exercise test values and selected performance times for the experienced and novice runners and for all runners combined are presented in Tables II and III, respectively. During the 7 weeks of training, the MSS training pace increased significantly from 3.76 to $4.19 \mathrm{~m} . \mathrm{s}^{-1}(11.3 \%)$. There were no statistically significant changes in body weight due to training. For all runners combined ( $n=12$ ), resting $H R$ and the HR response to submaximal exercise at $2.77 \mathrm{~m} . \mathrm{s}^{-1}$ were significantly reduced from 55 to 52 bt.min-1, and from 145 to 135 bt.min $^{-1}$, respectively, while maximal exercise heart rates were unchanged by MSS training. $\mathrm{VO}_{2}$ max-BW was significantly improved by $4.8 \mathrm{ml}^{.} \mathrm{kg}^{-1} \mathrm{~min}^{-1}(8.1 \%)$, while absolute $\mathrm{VO}_{2}$ max was increased by $0.35 \mathrm{I} \cdot \mathrm{min}^{-1}(8.9 \%) . \mathrm{VO}_{2}$ max-BW increased by $5.8 \%$ in the experienced runners and by $11.1 \%$ in the novice runners.

\section{TABLE ॥}

Selected physiologic measures prior to and after seven weeks of maximum steady state training in experienced (E) and novice (N) runners and for all and for all runners combined (C). Mean \pm S.D.

\begin{tabular}{|c|c|c|c|c|}
\hline Variable & Group & $\mathbf{N}$ & Pre-Training & Post-Training \\
\hline \multirow[t]{3}{*}{ HR rest (bt.min-1) } & C & 12 & $62 \pm 7$ & $52 \pm 7^{*}$ \\
\hline & $\mathbf{E}$ & 6 & $59 \pm 6$ & $50 \pm 6^{*}$ \\
\hline & $\mathbf{N}$ & 6 & $64 \pm 8$ & $55 \pm 8^{*}$ \\
\hline \multirow[t]{3}{*}{ HR sub (bt.min-1) } & C & 12 & $145 \pm 19$ & $135 \pm 20^{*}$ \\
\hline & $\mathbf{E}$ & 6 & $134 \pm 14$ & $125 \pm 9^{*}$ \\
\hline & $\mathbf{N}$ & 6 & $157 \pm 18$ & $146 \pm 23^{*}$ \\
\hline \multirow[t]{3}{*}{ HR max (bt.min-1) } & C & 12 & $189 \pm 8$ & $190 \pm 9$ \\
\hline & $\mathbf{E}$ & 6 & $191 \pm 5$ & $190 \pm 6$ \\
\hline & $\mathbf{N}$ & 6 & $188 \pm 11$ & $190 \pm 8$ \\
\hline \multirow[t]{3}{*}{$\mathrm{VO}_{2} \max \left(1 . \mathrm{min}^{-1}\right)$} & C & 12 & $3.94 \pm 0.43$ & $4.29 \pm 0.36^{*}$ \\
\hline & $\mathbf{E}$ & 6 & $4.22 \pm 0.27$ & $4.48 \pm 0.20^{*}$ \\
\hline & $\mathbf{N}$ & 6 & $3.65 \pm 0.38$ & $4.10 \pm 0.40^{*}$ \\
\hline \multirow[t]{3}{*}{$\mathrm{VO}_{2} \max -\mathrm{BW}\left(\mathrm{ml} \mathrm{kg}^{-1} \mathrm{~min}^{-1}\right)$} & C & 12 & $58.83 \pm 9.06$ & $63.62 \pm 8.29^{*}$ \\
\hline & $\mathbf{E}$ & 6 & $65.98 \pm 5.92$ & $69.82 \pm 4.29 *$ \\
\hline & $\mathbf{N}$ & 6 & $51.68 \pm 4.79$ & $57.42 \pm 6.10^{*}$ \\
\hline \multirow[t]{3}{*}{$A P \max (W)$} & C & 12 & $516 \pm 38$ & $553 \pm 39^{*}$ \\
\hline & $\mathbf{E}$ & 6 & $511 \pm 15$ & $523 \pm 39$ \\
\hline & $\mathbf{N}$ & 6 & $522 \pm 54$ & $546 \pm 45^{*}$ \\
\hline \multirow[t]{3}{*}{$A P \max \left(W \cdot \mathbf{k g}^{-1}\right)$} & C & 12 & $7.66 \pm 0.70$ & $8.00 \pm 0.72 *$ \\
\hline & $\mathbf{E}$ & 6 & $7.93 \pm 0.85$ & $8.19 \pm 0.95$ \\
\hline & $\mathbf{N}$ & 6 & $7.40 \pm 0.44$ & $7.80 \pm 0.40 *$ \\
\hline
\end{tabular}

*Significantly different pre- and post-training, $p<0.05$

For all runners combined, absolute AP max increased significantly from 516 to $535 \mathrm{~W}(3.7 \%)$, while AP max, relative to body weight increased from 7.66 to $8.00 \mathrm{~W} . \mathrm{kg}^{-1}$ $(4.3 \%)$. MSS training produced significant decreases in performance times for the $15 \mathrm{~m}$ run from 1.69 to $1.66 \mathrm{~s}$ $(1.8 \%)$, and for the $600 \mathrm{~m}$ run from 95 to $91 \mathrm{~s}(4.2 \%)$. In addition, $3.22 \mathrm{~km}$ run performance time decreased from 759 to $686 \mathrm{~s}(9.6 \%)$, while $10 \mathrm{~km}$ performance time decreased from 2902 to $2552 \mathrm{~s}$ (12.1\%). For the experienced runners, $3.22 \mathrm{~km}$ and $10 \mathrm{~km}$ performance times decreased by $4.3 \%$ and $6.7 \%$, respectively, while for the novice runners these decreases were $13.6 \%$ and $15.8 \%$, respectively. 


\section{TABLE III}

Selected performance indicators prior to and after seven weeks of maximum steady state training in experienced (E) and novice (N) runners and for all runners combined (C). Mean \pm S.D.

\begin{tabular}{|c|c|c|c|c|}
\hline Variable & Group & $\mathbf{N}$ & Pre-training & Post-training \\
\hline \multirow[t]{3}{*}{$15 \mathrm{~m}$ PT (s) } & C & 12 & $1.69 \pm 0.09$ & $1.66 \pm 0.10^{*}$ \\
\hline & $\mathbf{E}$ & 6 & $1.73 \pm 0.12$ & $1.72 \pm 0.10$ \\
\hline & $\mathbf{N}$ & 6 & $1.66 \pm 0.66$ & $1.62 \pm 0.07$ \\
\hline \multirow[t]{3}{*}{$600 \mathrm{~m}$ PT (s) } & C & 12 & $95.56 \pm 8.18$ & $91.32 \pm 7.31^{*}$ \\
\hline & $\mathbf{E}$ & 6 & $92.52 \pm 4.66$ & $87.93 \pm 3.71^{*}$ \\
\hline & $\mathbf{N}$ & 6 & $98.62 \pm 10.62$ & $94.72 \pm 9.25$ \\
\hline \multirow[t]{3}{*}{$3.22 \mathrm{~km}$ PT (s) } & C & 12 & $759.33 \pm 132.70$ & $686.75 \pm 83.68^{*}$ \\
\hline & $\mathbf{E}$ & 6 & $660.12 \pm 46.83$ & $632.00 \pm 15.44^{*}$ \\
\hline & $\mathbf{N}$ & 6 & $858.50 \pm 113.78$ & $741.50 \pm 89.29^{*}$ \\
\hline \multirow[t]{3}{*}{ 10km PT (s) } & C & 12 & $2902.66 \pm 663.42$ & $2552.50 \pm 451.33^{*}$ \\
\hline & $\mathbf{E}$ & 6 & $2385.00 \pm 209.88$ & $2225.17 \pm 102.94^{*}$ \\
\hline & $\mathbf{N}$ & 6 & $3420.33 \pm 530.16$ & $2879.83 \pm 424.73^{*}$ \\
\hline \multirow[t]{3}{*}{ MSS pace (m.s-1) } & C & 12 & $3.76 \pm 0.76$ & $4.19 \pm 0.57^{*}$ \\
\hline & $\mathbf{E}$ & 6 & $4.35 \pm 0.36$ & $4.56 \pm 0.14^{*}$ \\
\hline & $\mathbf{N}$ & 6 & $3.18 \pm 0.56$ & $3.81 \pm 0.60^{*}$ \\
\hline
\end{tabular}

*Significantly different pre- and post-training, $p<0.05$

Prior to MSS training, $10 \mathrm{~km}$ performance pace was significantly related to MSS pace $(r=0.98), \mathrm{VO}_{2}$ max-BW $(r=0.91)$, and $H R_{\text {sub }}(r=-0.83)$. Following MSS training, $10 \mathrm{~km}$ performance pace remained significantly related to MSS pace $(r=0.95), \mathrm{VO}_{2}$ max-BW $(r=0.89)$, and $H R_{\text {sub }}$ $(r=-0.84)$. In addition, post-training MSS pace was related to mean training pace $(r=0.97)$ and total training distance $(r$ $=-0.69$ ).

Furthermore, pre-training $10 \mathrm{~km}$ and $3.22 \mathrm{~km}$ performance time, $\mathrm{VO}_{2} \max -\mathrm{BW}$, and MSS pace were significantly related to decreases in performance times for the $3.22 \mathrm{~km}$ and $10 \mathrm{~km}$ runs and in MSS pace (Table IV), but unrelated $(p>0.05)$ to changes in AP max and AP max.kg-1, and $15 \mathrm{~m}$ and $600 \mathrm{~m}$ performance times.

\section{TABLE IV}

Significant ( $p<0.05$ ) Pearson Product Moment correlation coefficients relating changes in maximum steady state (MSS) pace and performance times to pre-training values of $\mathrm{VO}_{2}$ max and running performance

\begin{tabular}{lccc}
\hline Variables* & $\Delta M S S$ pace & $\Delta 3.22 \mathrm{~km}$ time & $\Delta 10 \mathrm{~km}$ time \\
\hline VO, max-BW & -0.73 & -0.81 & -0.86 \\
MSS pace & -0.73 & -0.87 & -0.90 \\
$3.22 \mathrm{~km}$ time & 0.69 & 0.87 & 0.87 \\
$10 \mathrm{~km}$ time & 0.61 & 0.79 & 0.93
\end{tabular}

*variables represent pre-training values

\section{DISCUSSION}

In our study, we found that MSS training significantly improved $\mathrm{AP}$ max and $\mathrm{VO}_{2}$ max, and performance times for the $15 \mathrm{~m}, 600 \mathrm{~m}, 3.22 \mathrm{~km}$ and $10 \mathrm{~km}$ runs. Our findings suggest that MSS training improves both maximal aerobic and anaerobic power, and improves physical performance which utilises a combination of the aerobic and anaerobic energy yielding systems. Thus, our findings provide evidence in support of the concept of MSS pace training.

In addition, we found that maximal aerobic power, MSS for the $3.22 \mathrm{~km}$ runs, and performance times for the $3.22 \mathrm{~km}$ and $10 \mathrm{~km}$ runs prior to MSS training were good predictors of improvement in MSS training pace and improvement in performance times for $3.22 \mathrm{~km}$ and $10 \mathrm{~km}$, but poor predictors $(p>0.05)$ of improvement in the anaerobic (AP $\max$ and $15 \mathrm{~m})$ and anaerobic-aerobic $(600 \mathrm{~m})$ performance events. The experienced runners improved their $\mathrm{VO}_{2}$ maxBW, MSS training pace, and performance times for the $3.22 \mathrm{~km}$ and $10 \mathrm{~km}$ runs by $5.8 \%, 4.9 \%, 4.2 \%$ and $6.7 \%$, respectively, while in the novice runners these improvements were $11.1 \%, 20.0 \%, 13.6 \%$ and $15.8 \%$, respectively. Thus, the maximal aerobic power capacity of a runner appears to be an important indicator of the effectiveness of MSS training.

Our findings support the view that endurance training increases $\mathrm{VO}_{2}$ max and decreases performance times for distance running events and that the magnitude of improvement of these measures of maximal aerobic power are dependent upon the pre-training level of $\mathrm{VO}_{2}$ max. The significant relation between maximal aerobic power and improvement in performance times for the middle-distance running events suggests that MSS training may be more effective for individuals with an initially low level of maximal aerobic power. The increase in running performance of the novice runners was accompanied by increases in $\mathrm{VO}_{2}$ max as well as increases in AP max, while the improvements in running performance of the experienced runners was mediated by an increased $\mathrm{VO}_{2}$ max. Thus, our findings suggest that this disproportionate effect may be due to the lack of increase in AP max of the experienced runners.

It is known that highly conditioned athletes are able to produce and tolerate higher exercise lactate levels than less conditioned individuals (Åstrand and Rodahl, 1977). In addition, it has been suggested that training at a blood lactate level of $4.0 \mathrm{mmol} . \mathrm{I}^{-1}$ is a more appropriate exercise intensity for the improvement of cardiorespiratory functional capacity (Kinderman et al, 1979; Sjödin and Jacobs, 1981; Yoshida et al, 1980). Furthermore, it has been suggested that runners might require "endurance-interval" training programmes equivalent to 90 to $100 \%$ of $\mathrm{VO}_{2}$ max in order to increase the anaerobic threshold and produce improvements in performance (MacDougall and Sale, 1981). For some runners the LaFontaine $3.22 \mathrm{~km}$ equation may predict a running pace which is too low of an intensity for optimal gains in cardiovascular endurance. It may be that runners with high maximal aerobic power and a wellestablished training foundation must work at higher blood lactate values. Additional high intensity "enduranceinterval" training which produces higher blood lactate levels may be necessary for those runners who demonstrate little or no improvement with MSS training.

Parenthetically, it must be remembered that the regression equations developed by LaFontaine et al (LaFontaine et al, 1981) are specific for the subjects from which they were derived. Compared to LaFontaine's subjects, our subjects were younger, and more heterogeneous for $\mathrm{VO}_{2}$ max and training history. For this reason, prediction of specific MSS running paces from the regression equations of LaFontaine et al should be made with caution. These regression equations should be considered only as general predictors of a MSS training pace.

In conclusion, utilisation of the LaFontaine $3.22 \mathrm{~km}$ 
equation to determine MSS training pace can be considered a practical method of determining an individual's training pace for the $10 \mathrm{~km}$ distance, and as an effective method to increase maximal anaerobic and aerobic performance. However, MSS training for the $10 \mathrm{~km}$ distance will have its greatest effect on runners with a low $\mathrm{VO}_{2}$ max, while runners with a high $\mathrm{VO}_{2}$ max may need to work at a higher level of their maximal aerobic power.

\section{References}

Astrand, P.-O. and Rodahl, K., 1977. Textbook of Work physiology. McGrawHill, New York, p. 433.

Bruce, R. A., 1971 "Exercise testing of patients with coronary heart disorders". Ann.Clin.Res. 3: 323.

Costill, D. L., Thomason, H. and Roberts, E., 1973 "Fractional utilization of the aerobic capacity during running". Med.Sci.Sports Ex. 5: 248-252.

Farrell, D. A., Wilmore, J. H., Coyle, E. F., Billing, J. E., Costill, D. L., 1979 "Plasma lactate accumulation and distance running performance". Med.Sci.Sports Ex. 11: 338-344.

Katch, V., Weltman, A., Martin, R. and Gray, L., 1974 "Optimum test characteristics for maximal anaerobic work on a bicycle ergometer". Res.Quart. 25: 164-177.
Kindermann, W., Simon, G. and Keul, J., 1979 "The significance of the aerobic-anaerobic transition for the determintion of work load intensities during endurance training". Eur.J.Appl.Physiol. 42: 25-34.

Komi, P. V., Ito, A., Sjödin, B., Wallenstein, R. and Karlsson, J., 1981 “Muscle metabolism, lactate breaking point, and biomechanical features of endurance running". Int.J.Sports Med. 2: 148-153.

Kumugai, S., Tanaka, K., Matsura, Y., Matsuzaka, A., Hinakoba, K. and Asano, K., 1982 "Relationship of the anaerobic threshold with the $5 \mathrm{~km}, 10 \mathrm{~km}$, and 10 mile races". Eur.J.Appl.Physiol. 49: 13-23.

LaFontaine, T., Londeree, B. and Spath, W., 1981 "The maximum steady state versus selected running events". Med.Sci.Sports Ex. 13: 190-192.

Londeree, B. R., Ames, S. A., 1975 "Maximal Steady State Versus State of Conditioning". Eur.J.Appl.Physiol. 34: 269-278.

MacDougall, F. D. and Sale, D., 1981 "Continuous vs. interval training: A review for the athlete and the coach". Canad.J.Appl.Sports Sci. 6: 93-97.

Siegel, S., 1956. Nonparametric statistics for the behavioral sciences. McGraw-Hill, New York.

Sjödin, B. and Jacobs, I., 1981 "Onset of blood lactate accumulation and marathon running performance". Int.J.Sports Med. 2: 23-26.

Williams, L. G., Wyndham, C. H., Kok, R. and von Rahden, M. J. E., 1967 "Effect of training on maximal oxygen intake and on anaerobic metabolism in man". Int.Z.ang.physiol. 24: 18-23.

Yoshida, T., Suda, Y. and Tabeuchi, N., 1980 "Endurance training regimen based upon arterial blood lactate: Effects on anaerobic threshold". Eur.J.Appl.Physiol. 49: 223-230.

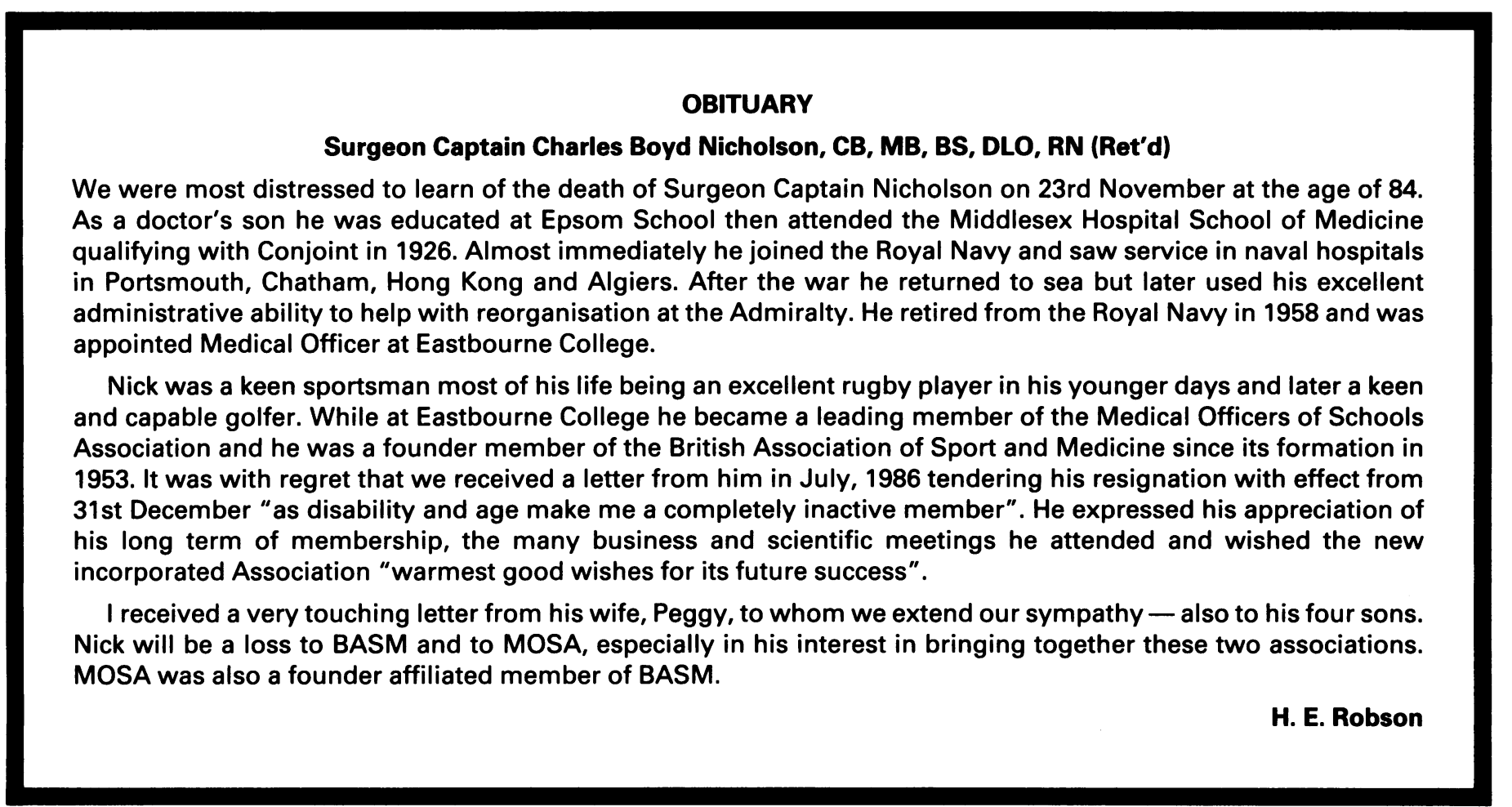

We were most distressed to learn of the death of Surgeon Captain Nicholson on 23rd November at the age of 84. As a doctor's son he was educated at Epsom School then attended the Middlesex Hospital School of Medicine qualifying with Conjoint in 1926. Almost immediately he joined the Royal Navy and saw service in naval hospitals in Portsmouth, Chatham, Hong Kong and Algiers. After the war he returned to sea but later used his excellent administrative ability to help with reorganisation at the Admiralty. He retired from the Royal Navy in 1958 and was incorporated Association "warmest good wishes for its future success".

I received a very touching letter from his wife, Peggy, to whom we extend our sympathy - also to his four sons. MOSA was also a founder affiliated member of BASM. 